\title{
The early dynamic behavior of lactate is linked to mortality in postcardiotomy patients with extracorporeal membrane oxygenation support: A retrospective observational study
}

\author{
Cheng-Long Li, MD, ${ }^{\mathrm{a}}$ Hong Wang, MD, PhD, ${ }^{\mathrm{a}}$ Ming Jia, MD, ${ }^{\mathrm{a}}$ Ning Ma, MD, PhD, ${ }^{\mathrm{b}}$ Xu Meng, MD,${ }^{\mathrm{c}}$ and \\ Xiao-Tong Hou, $\mathrm{MD}, \mathrm{PhD}^{\mathrm{a}}$

\begin{abstract}
Objective: Extracorporeal membrane oxygenation (ECMO) is used to support postcardiotomy cardiogenic shock patients. Elevated serum lactate levels might reflect hypoxia in the tissues, which is associated with mortality in critically ill patients. This study examined the association between the early dynamic behavior of lactate and mortality after ECMO support.
\end{abstract}

Methods: We included 123 adult patients who had undergone cardiac surgery and received venous-arterial ECMO implantation to treat refractory postcardiotomy cardiogenic shock. The dynamic behaviors of lactate within 6 hours and 12 hours after the beginning of the ECMO support were incorporated into 2 regression models.

\begin{abstract}
Results: A total of $56 \%$ of the patients were successfully weaned from ECMO support. The in-hospital mortality was $65.9 \%$ overall. Univariate and multivariate analyses indicated that age (odds ratio [OR]: 1.1 in the 6-hour model; 1.1 in the 12-hour model), gender (female; OR: 5.6 in the 6-hour model; 7.7 in the 12-hour model), mean lactate concentration (OR: 1.1 in the 6-hour model; 1.2 in the 12-hour model) and lactate clearance (OR: 0.5 in the 6-hour model; 0.1 in the 12 -hour model) were reliable predictors $(P<.05)$ of in-hospital mortality. The mean lactate concentration (C statistic: 0.71$)$ and lactate clearance (C statistic: 0.72$) 12$ hours after the initiation of ECMO support provided better prognostic guidance. The mean lactate concentration (OR: 1.2) and lactate clearance (OR: 0.3) were able to predict successful weaning from ECMO in the 12-hour model only.
\end{abstract}

Conclusions: In addition to age and gender (female), early lactate behaviors, particularly lactate clearance, after ECMO support are highly associated with in-hospital mortality in postcardiotomy patients. Additionally, early lactate behavior is also predictive of successful weaning from ECMO. (J Thorac Cardiovasc Surg 2015;149:1445-50)

See related commentary pages $1451-2$.

Cardiac surgery is an important procedure for patients with heart disease. Postcardiotomy cardiogenic shock (PCS) is a life-threatening complication with an incidence that ranges from $0.5 \%$ to $1.5 \%$ in adult cardiac surgery patients. ${ }^{1}$ Because left ventricular assist devices are not registered in People's Republic of China, extracorporeal membrane oxygenation (ECMO) is our major alternative for temporary mechanical circulatory support. This technique facilitates cardiac and pulmonary recovery, despite the use of

\footnotetext{
From the Center for Cardiac Intensive Care, ${ }^{\mathrm{a}}$ and Departments of Echocardiography ${ }^{\mathrm{b}}$ and Cardiac Surgery, ${ }^{\mathrm{c}}$ Beijing Anzhen Hospital, Capital Medical University, Beijing, People's Republic of China.

This work was supported by grants from the National Natural Science Foundation of China (No. 81270327, 81470528 to X-T. H.), the Research Fund of Capital Medical Development (2014-1-1051 to X-T. H.), and the Beijing Municipal Science and Technology Commission-Funded Project (Z111107067311038 to N.M.).

Disclosures: Authors have nothing to disclose with regard to commercial support.

Received for publication Aug 27, 2014; revisions received Oct 31, 2014; accepted for publication Nov 19, 2014; available ahead of print Dec 19, 2014.

Address for reprints: Xiao-Tong Hou, MD, PhD, Center for Cardiac Intensive Care, Beijing Anzhen Hospital, Capital Medical University, 2 Anzhen Rd, Chaoyang District, Beijing, 100029, People's Republic of China (E-mail: xt.hou@ccmu.edu.cn). $0022-5223 / \$ 36.00$

Copyright (C) 2015 by The American Association for Thoracic Surgery

http://dx.doi.org/10.1016/j.jtcvs.2014.11.052
}

inotropic agents and optimal medical management in PCS patients. $^{2}$ In-hospital mortality ranges from $60 \%$ to $80 \%,{ }^{1,3-5}$ with successful ECMO weaning rates ranging from $30 \%$ to $60 \%$, as reported. ${ }^{6}$

Lactate is a metabolic end product of anaerobic glycolysis that is produced by the reduction of pyruvate and primarily removed by the liver. ${ }^{7,8}$ Lactate has been proposed as a marker of tissue perfusion that is influenced by not only macrocirculation but also microcirculation (ie, the network of arterioles, capillaries, and venules), whereas traditional hemodynamic parameters have been suggested to be unreliable. ${ }^{9}$ Lactate has been proven to be associated with increased risks of death in infection, ${ }^{10}$ sepsis, ${ }^{11}$ trauma, ${ }^{12}$ and operations, ${ }^{13}$ including cardiac surgery. ${ }^{14,15}$ In addition, the lactate levels of intra-aortic balloon pump $(\text { IABP })^{16}$ and ECMO-supported ${ }^{17,18}$ patients might be predictors of mortality. However, the dynamic behavior of lactate is rarely referenced. The primary aim of this investigation was to examine the association between the dynamic behavior of lactate and mortality in postcardiotomy patients under ECMO support.

\section{METHODS}

\section{Patients}

With the approval of the Institutional Review Board of Beijing Anzhen Hospital, Capital Medical University, Beijing, People's Republic of China, 


\section{Abbreviations and Acronyms \\ $\mathrm{CABG}=$ (on-pump) coronary artery bypass graft \\ $\mathrm{ECMO}=$ extracorporeal membrane oxygenation \\ $\mathrm{IABP}=$ intra-aortic balloon pump \\ MAP $=$ mean artery pressure \\ $\mathrm{OR}=$ odds ratio \\ PCS $=$ postcardiotomy cardiogenic shock}

a retrospective analysis was performed at a university-affiliated cardiac surgical intensive-care unit over a 2-year period from January 2011 to December 2012. The requirement for individual patient consent was waived because this study was based on anonymized data from routine care. A total of 123 of 13,538 (0.9\%) adult patients undergoing cardiac surgery received venous-arterial ECMO implantation to treat refractory PCS. ECMO was initiated intraoperatively in the operating room for circulatory instability during or immediately after weaning from the cardiopulmonary bypass in the primary cardiac procedure. The capability to institute ECMO secondarily in the intensive-care unit, for delayed PCS, was available. The secondary indications included intractable ventricular arrhythmia or fibrillation, progressive univentricular or biventricular failure, or sudden idiopathic heart failure. The clinical criteria for PCS include systolic arterial hypotension $(<80 \mathrm{~mm} \mathrm{Hg})$, increased central venous pressure exceeding $12 \mathrm{~mm} \mathrm{Hg}$, signs of end-organ failure (urinary flow rate $<0.5 \mathrm{~mL} / \mathrm{kg}$ ), and metabolic acidosis $(\mathrm{pH}<7.3$, lactate level $>3.0 \mathrm{mmol} / \mathrm{L})$ despite optimized supportive measures, such as an IABP, inotropes, nitric oxide, and phosphodiesterase inhibitors.

\section{Extracorporeal Membrane Oxygenation Circuit}

The ECMO circuit was completely implanted via peripheral cannulation through the femoral route with the cut-down method. A distal leg perfusion cannula was introduced to prevent lower-extremity ischemia. Before cannulation, a bolus of heparin (100 units $/ \mathrm{kg}$ ) was given intravenously, and the activated clotting time was measured at $>180$ seconds. The ECMO circuit was primed with normal saline containing heparin at a concentration of $2 \mathrm{IU} / \mathrm{ml}$. The ECMO circuit consisted of a centrifugal pump console (Bio-Pump PB-80, Medtronic BioMedicus, Eden Prairie, Minn; or Jostra RotaFlow centrifugal pump, Maquet, Hirrlingen, Germany) in conjunction with an inline plasma-tight hollow-fiber microporous membrane oxygenator (Affinity NTTM, Medtronic, Anaheim, Calif; or Hilite 7000 LTTM, Medos Medizintechnik AG, Stolberg, Germany) with an integrated heat exchanger.

\section{Management Strategy}

The mixed venous oxygen saturation was kept at $60 \%$ by adjusting the ECMO pump flow. Oxygen flow was titrated to maintain a postoxygenator partial oxygen pressure of $\geq 300 \mathrm{~mm} \mathrm{Hg}$. Carbon dioxide was maintained within the normal range by adjusting the sweep flow. The heat exchanger temperature was set to maintain the patient's normal temperature. Inotropic agents were minimized to allow for optimal myocardial recovery, and the left ventricular ejection was simultaneously maintained to avoid thrombus formation inside the left ventricle. Support with an IABP was employed in some cases to decrease afterload and to increase coronary perfusion and pulsatility. The activated clotting time was measured every 4 hours to achieve levels of 160-180 seconds via continuous intravenous heparin administration. The hematocrit was maintained at $30 \%$ to $35 \%$ by packed red blood cell transfusion. Platelets were transfused when the patient's platelet count decreased to $<50 \times 10^{3} / \mathrm{mm}^{3}$. Midazolam and fentanyl were routinely used to sedate the patients.
All of the patients were ventilated on the volume-controlled ventilation mode at 10 breaths $/ \mathrm{min}$. The ventilator was commonly set at a tidal volume of 6-8 $\mathrm{ml} / \mathrm{kg}$ with a positive end-expiration pressure of 6-8 $\mathrm{mm} \mathrm{Hg}$ to prevent alveolar collapse, and the inspired oxygen fraction was $40 \%$.

The circuit was checked daily and changed if hemolysis or thrombocythemia occurred, if significant fibrin depositions or clots accumulated on the membrane, or if the blood oxygenation ability faltered. Weaning was cautiously initiated only under stable hemodynamic and metabolic conditions. The full flow was decreased gradually to $1 \mathrm{~L} / \mathrm{min}$ over $36-48$ hours while observing the echocardiograph, metabolic status, venous saturation, and end-organ perfusion. The medicine was adjusted when necessary. The ECMO was removed at the patient's bedside under intravenous anesthesia, and the patient's vessels were primarily repaired. Successful weaning was defined by the lack of obvious hemodynamic deterioration for at least 48 hours after the removal of the ECMO support.

The adverse outcomes were defined as follows: leg ischemia (pallor, pulselessness, gangrene), multiple organ dysfunction syndrome (failure of $>2$ organs including renal failure, hepatic failure, neurologic dysfunction, and disseminated intravascular coagulation), infection (as proven by blood or sputum cultures obtained during ECMO support), stroke (cerebrovascular accident with neurologic impairment), and "re-do surgeries" (cardiac surgery of any cause after any previous cardiac surgical procedure).

\section{Setting of the Parameters}

The first arterial blood gas that contained arterial serum lactate concentrations was taken 0.5 to 1 hours after the ECMO support had commenced. Next, the arterial blood gas was measured approximately every 4 hours. In addition, the blood pressures and the times at which the blood samples were taken were recorded. The arterial lactate concentrations obtained during the first 6 hours and 12 hours after the ECMO support had commenced were averaged. The mean lactate concentration was useful but did not suggest directional information or indicate whether a patient was improving or worsening.

Lactate clearance was calculated by linear regression of the lactate concentrations over time, and the unit of lactate clearance was $\mathrm{mmol} / \mathrm{L} \cdot$ hour. Lactate clearance was positive when the lactate concentration went down, and this measure represented the dynamic behavior of lactate. The mean lactate concentrations and the lactate clearances after 6 hours (ie, the 6hour model) and 12 hours (ie, the 12-hour model) from the initiation of ECMO support were individually incorporated into 2 regression models. The inotrope score was calculated when the inotrope agent adequately maintained a relatively stable hemodynamic status according to the following formula ${ }^{19}$ : dosages of dopamine (in $\mu \mathrm{g} / \mathrm{kg} \cdot \mathrm{min}$ ) + dosages of dobutamine (in $\mu \mathrm{g} / \mathrm{kg} \cdot \min )+$ [dosages of epinephrine (in $\mu \mathrm{g} / \mathrm{kg}$. $\min )+$ norepinephrine (in $\mu \mathrm{g} / \mathrm{kg} \cdot \min )] \times 100+$ dosages of pituitrin $($ in $\mathrm{u} / \mathrm{min}) \times 100+$ dosages of milrinone $($ in $\mu \mathrm{g} / \mathrm{kg} \cdot \mathrm{min}) \times 15$.

\section{Statistical Methods}

Continuous variables are expressed as mean $\pm \mathrm{SD}$. The categoric data are given as numbers or proportions. Independent continuous variables were compared with 2-tailed Student $t$ tests or Mann-Whitney $U$ tests, as appropriate. Categoric variables were compared with the Pearson $\chi^{2}$ statistic. Univariate and stepwise multivariate logistic regressions were used to analyze the predictors of in-hospital mortality. C statistics are reported and were used in this investigation to help determine the accuracy of the selected measures in the predictions of the selected outcomes. Linear correlations were used to analyze the relationships between the continuous variables. All statistical calculations were performed with SPSS 19.0 (SPSS, Inc, Chicago, Ill).

\section{RESULTS}

Over the 2-year period, 123 patients received ECMO support during their ICU admissions for cardiac surgery. The 
mean age of the patients was $56.2 \pm 11.8$ years (range, 18 to 76 years). Eighty-one were male; 42 were female. The cardiac surgeries included off-pump coronary artery bypass graft, on-pump coronary artery bypass graft (CABG), CABG combined valve procedure, CABG combined left ventricular aneurysm plasty, valve procedure, heart transplantation, and other procedures. ECMO support was initiated in the operating room for 61 patients, owing to circulatory instability during or immediately after weaning from the cardiopulmonary bypass. Sixty-two patients received ECMO support for delayed PCS and resuscitation in the ICU. The ECMO implantations were successful in all cases.

The characteristics of the survivors and nonsurvivors are illustrated and compared in Table 1. Obvious left ventricle distension was not observed in either group. The survivors and nonsurvivors were statistically similar with the exceptions of age $(51.0 \pm 12.2$ vs $58.9 \pm 10.7$ years, respectively, $P<.001$ ), gender (33 men and 9 women vs 48 men and 33 women, respectively, $P=.03)$, epinephrine used $(0.14 \pm$ 0.39 vs $0.17 \pm 0.24 \mu \mathrm{g} / \mathrm{kg} \cdot \min$, respectively, $P=.001)$, and inotrope score $(19.7 \pm 8.9$ vs $35.3 \pm 41.5$, respectively, $P=.02)$.

Of the 123 patients, $69(56.1 \%)$ patients were successfully weaned from the ECMO support. ECMO support lasted $4.4 \pm 3.7$ days on average. Overall, the in-hospital mortality was $65.9 \%$. Table 2 shows the outcomes of ECMO support for the survivors and nonsurvivors. Fewer adverse outcomes occurred in the survivors compared to the nonsurvivors, and significant differences were observed between these groups in leg ischemia ( $0 \%$ vs $24.7 \%$, respectively, $P<.001)$, multiple organ dysfunction syndrome $(0 \%$ vs $13.6 \%$, respectively, $P=.03)$, and continuous renal replacement therapy ( $7.1 \%$ vs $32.1 \%$, respectively, $P=.002$ ). The survivors exhibited a longer ICU length of stay $(7.9 \pm 3.7$ vs $7.2 \pm 7.0, P=.04)$ and a longer hospital length of stay $(24.3 \pm 13.9$ vs $10.0 \pm 10.9, P<.001)$ compared to the nonsurvivors.

The survivors exhibited a lower lactate concentration $(9.4 \pm 4.2$ vs $13.3 \pm 5.4 \mathrm{mmol} / \mathrm{L}, P<.001,12$-hour model $)$ and a higher lactate clearance $(0.55 \pm 0.40$ vs $0.23 \pm 0.47 \mathrm{mmol} / \mathrm{L} \cdot$ hour, $P=.001,12$-hour model) than did the nonsurvivors. To acquire direct insight into the differences in lactate behaviors between the survivors and nonsurvivors, the lactate data that were acquired at nonfixed intervals were split into the following 5 stages (Figure 1): baseline (before the initiation of ECMO; $11.3 \pm 5.8 \mathrm{mmol} / \mathrm{L}$ vs $13.1 \pm 5.4, P=.086), 0$ to 1 hours $(12.4 \pm 5.2 \mathrm{mmol} / \mathrm{L}$ vs $14.3 \pm 5.2, P=.047), 4$ to 5 hours $(10.5 \pm 5.0 \mathrm{mmol} / \mathrm{L}$ vs $13.6 \pm 5.5, P=.004), 8$ to 9 hours $(8.3 \pm 4.3 \mathrm{mmol} / \mathrm{L}$ vs $11.8 \pm 5.7, P=.003)$, and 12 to 13 hours $(6.4 \pm 3.8 \mathrm{mmol} / \mathrm{L}$ vs $10.6 \pm 5.7, P<.001)$ after the initiation of ECMO.
TABLE 1. Characteristics and comparisons of survivors and nonsurvivors

\begin{tabular}{|c|c|c|c|}
\hline $\begin{array}{l}\text { Characteristic and } \\
\text { comparison factor }\end{array}$ & $\begin{array}{c}\text { Survivors } \\
(\mathrm{n}=\mathbf{4 2})\end{array}$ & $\begin{array}{l}\text { Nonsurvivors } \\
\quad(\mathbf{n}=\mathbf{8 1})\end{array}$ & $\begin{array}{c}P \\
\text { value }\end{array}$ \\
\hline Age (y) & $51.0 \pm 12.2$ & $58.9 \pm 10.7$ & $<.001$ \\
\hline Male/female (\%) & $78.6 / 21.4$ & $59.3 / 40.7$ & .03 \\
\hline $\operatorname{BSA}\left(\mathrm{m}^{2}\right)$ & $1.7 \pm 0.2$ & $1.7 \pm 0.2$ & .97 \\
\hline Type of surgery (n) & & & .49 \\
\hline Off-pump CABG & 11 & 18 & \\
\hline CABG & 2 & 13 & \\
\hline $\mathrm{CABG}+$ valve procedure & 3 & 9 & \\
\hline $\begin{array}{l}\text { CABG }+ \text { LV aneurysm } \\
\text { plasty }\end{array}$ & 3 & 0 & \\
\hline Valve procedure & 13 & 27 & \\
\hline HTX & 5 & 6 & \\
\hline Others & 5 & 8 & \\
\hline CPB (n) & 29 & 63 & .39 \\
\hline Preoperative LVEF (\%) & $52.2 \pm 15.7$ & $55.8 \pm 12.3$ & .41 \\
\hline Preoperative LVEDD (mm) & $54.4 \pm 15.5$ & $53.0 \pm 9.9$ & .93 \\
\hline NYHA class III or IV $(\%)$ & 71.4 & 60.5 & .23 \\
\hline $\begin{array}{l}\text { Commencement of ECMO } \\
\text { support (n) }\end{array}$ & & & .49 \\
\hline During surgery & 19 & 42 & \\
\hline Postsurgery & 23 & 39 & \\
\hline Pump flow (L/min) & $2.9 \pm 0.6$ & $3.0 \pm 0.9$ & .36 \\
\hline IABP support (n) & 24 & 49 & .72 \\
\hline \multicolumn{4}{|l|}{ After initiation of ECMO } \\
\hline ALT & $288.5 \pm 512.7$ & $427.9 \pm 985.6$ & .54 \\
\hline AST & $727.9 \pm 1331.4$ & $1234.8 \pm 3501.2$ & .26 \\
\hline $\begin{array}{l}\text { Mean glucose in } 12 \mathrm{~h} \\
(\mathrm{mg} / \mathrm{dl})\end{array}$ & $260.2 \pm 85.1$ & $260.8 \pm 93.9$ & .86 \\
\hline \multicolumn{4}{|l|}{ Inotrope agents infused } \\
\hline Dopamine $(\mu \mathrm{g} / \mathrm{kg} \cdot \min )$ & $5.6 \pm 2.9$ & $7.6 \pm 5.9$ & .15 \\
\hline Epinephrine $(\mu \mathrm{g} / \mathrm{kg} \cdot \min )$ & $0.14 \pm 0.39$ & $0.17 \pm 0.24$ & .00 \\
\hline $\begin{array}{l}\text { Norepinephrine } \\
\qquad(\mu \mathrm{g} / \mathrm{kg} \cdot \mathrm{min})\end{array}$ & $0.05 \pm 0.09$ & $0.07 \pm 0.16$ & .61 \\
\hline Inotrope score & $19.7 \pm 8.9$ & $35.3 \pm 41.5$ & .02 \\
\hline
\end{tabular}

$B S A$, Body surface area; $C A B G$, (on-pump) coronary artery bypass graft; $L V$, left ventricular; $H T X$, heart transplantation; $C P B$, cardiopulmonary bypass; $L V E F$, left ventricle eject fraction; $L V E D D$, left ventricular end-diastolic dimension; $N Y H A$, New York Heart Association; ECMO, extracorporeal membrane oxygenation $I A B P$, intra-aortic balloon pump; $A L T$, alanine aminotransferase; $A S T$, aspartate aminotransferase.

Univariate and multivariate analyses indicated that age, gender, mean lactate concentration, and lactate clearance were independent predictors of in-hospital mortality in both the 6-hour and 12-hour models (Table 3). The odds ratios (ORs) and $\mathrm{C}$ statistics for the independent predictors and predicting models are shown in Table 3. Receiver operating characteristic curves suggested that the 12-hour parameters performed better in predicting mortality. The mean lactate concentration (OR: $1.2, P<.001)$ and the lactate clearance (OR: $0.3, P=.023)$ were able to predict successful weaning from ECMO in the 12-hour model only.

The correlations between the parameters describing the lactate behaviors and those that might have affected the 
TABLE 2. Outcomes and comparisons of survivors versus nonsurvivors

\begin{tabular}{lccc}
\hline Comparison factor and outcome & $\begin{array}{c}\text { Survivors } \\
(\mathbf{n}=\mathbf{4 2})\end{array}$ & $\begin{array}{c}\text { Nonsurvivors } \\
(\mathbf{n}=\mathbf{8 1})\end{array}$ & $\begin{array}{c}\boldsymbol{P} \\
\text { value }\end{array}$ \\
\hline Total blood products transfusions & & & \\
$\quad$ Red blood cells (units) & $19.4 \pm 10.9$ & $19.5 \pm 13.1$ & .72 \\
Fresh-frozen plasma $\left(10^{2} \mathrm{ml}\right)$ & $20.1 \pm 15.9$ & $18.5 \pm 11.6$ & .94 \\
$\quad$ Platelets (units) & $4.1 \pm 4.1$ & $2.7 \pm 3.5$ & .06 \\
Leg ischemia (\%) & 7.7 & 22.2 & .04 \\
MODS (\%) & 0 & 13.6 & .03 \\
Infection (\%) & 9.5 & 14.8 & .41 \\
Stroke (\%) & 0 & 6.2 & .25 \\
"Re-do" surgeries (\%) & 40.5 & 39.5 & .92 \\
CRRT (\%) & 7.1 & 32.1 & .002 \\
ECMO assisting time, d & $4.6 \pm 1.9$ & $4.2 \pm 4.4$ & .01 \\
Ventilation time, h & $135.9 \pm 144.9$ & $139.4 \pm 146.5$ & .84 \\
ICU LOS, d & $7.9 \pm 3.7$ & $7.2 \pm 7.0$ & .04 \\
Hospital LOS, d & $24.3 \pm 13.9$ & $10.0 \pm 10.9$ & $<.001$ \\
\hline MODS, Multiple organ dysfunction syndrome; CRRT, continuous renal replacement \\
therapy; ECMO, extracorporeal membrane oxygenation; ICU, intensive-care unit; \\
LOS, length of stay.
\end{tabular}

lactate behaviors are shown in Table 4 . There was a negative linear correlation between the average mean artery pressure (MAP) and the mean lactate concentration, but positive linear correlations were noted between the inotrope used (with the exception of the dopamine used and the 6-hour mean lactate concentration), liver enzymes (alanine aminotransferase and aspartate aminotransferase) and mean lactate concentration. The 6-hour lactate clearance was not correlated with any of the parameters that might have affected it in this study. In contrast, the 12-hour lactate clearance was negatively correlated with the dopamine used and the 2 liver enzymes, and positively correlated with the 12-hour average MAP. The ECMO pump flow



FIGURE 1. Lactate behaviors before and after initiation of ECMO. $E C M O$, Extracorporeal membrane oxygenation. *Significant $(P<.05)$ differences between the 2 groups. and red blood cell transfusion were not correlated with any of the lactate behaviors.

\section{DISCUSSION}

Extracorporeal membrane oxygenation is a better choice of mechanical circulatory support than IABP for PCS patients who are not amenable to IABP support alone. Reasons include ECMO's easy application, its support of both the right and left ventricles, and its partial substitution for lung function. However, the survival rate $(44 \%)$ with use of cardiac extracorporeal life support has plagued clinicians for decades. ${ }^{20}$ Our retrospective study identified that age (OR: 1.1 in the 6-hour model and 1.1 in the 12-hour model) and gender (female; OR: 6.3 in the 6-hour model and 7.7 in the 12-hour model) were able to provide accurate predictions of in-hospital mortality for the patients who underwent ECMO support. However, in agreement with other investigations, ${ }^{1,17,21,22}$ these 2 parameters were not able to provide clinical information during the early course of ECMO support. Based on these parameters, clinicians are unable to make further decisions regarding fluid resuscitation, changes in pump flow, dosages of inotropes, or further device assistance.

Our investigation revealed that early lactate behavior following the initiation of ECMO support can predict inhospital mortality in postcardiotomy patients. An elevated mean lactate concentration and a low lactate clearance in the first 6 hours and 12 hours after the initiation of ECMO were associated with increased mortality in the univariate and multivariate analyses. Independently of age and gender, the level and dynamic behavior of lactate provided clinically relevant information about global tissue perfusion and direction. Lactate clearance and concentration were found to exhibit a better combination of sensitivity and specificity in the 12-hour model than in the 6-hour model (C statistics: 0.71 vs 0.66 for mean lactate concentration, and 0.72 vs 0.68 for lactate clearance). The superior performance of the lactate behavior in the 12-hour model might have resulted from the time that is required for lactate production to be detected. In some cases, we observed that the lactate concentration continued to rise after a good hemodynamic status was achieved; ie, the organs were well perfused before the lactate concentration began to diminish. Thus, the 12-hour model allowed for a longer period for the observation of lactate behavior.

The mean lactate concentration and lactate clearance in the 12-hour model were able to predict successful weaning of patients receiving ECMO support. These results suggest that lactate behaviors might be indicative of the global functioning or cardiac functioning of the patient only at the time of PCS or of implantation of the ECMO circuit. Patients with better global status and less impairment of heart function might exhibit better cardiac recovery and be more likely to experience successful weaning from ECMO. 
TABLE 3. Factors associated with in-hospital mortality

\begin{tabular}{|c|c|c|c|c|c|c|}
\hline \multirow[b]{2}{*}{ Variable } & \multirow[b]{2}{*}{ Survivors $(n=42)$} & \multirow[b]{2}{*}{ Nonsurvivors $(\mathbf{n}=\mathbf{8 1})$} & \multirow{2}{*}{$\frac{\text { Univariate analysis }}{P \text { value }}$} & \multicolumn{3}{|c|}{ Multivariate analysis } \\
\hline & & & & $P$ value & OR $(95 \%$ CI $)$ & C statistic \\
\hline Regression model of 6-h parameters & & & & & & 0.81 \\
\hline Age (y) & $51.0 \pm 12.2$ & $58.9 \pm 10.7$ & .001 & .002 & $1.1(1.0-1.1)$ & 0.70 \\
\hline Female $(\%)$ & 21.4 & 40.7 & .04 & .001 & $6.3(2.1-19.6)$ & 0.60 \\
\hline Mean lactate concentration $(\mathrm{mmol} / \mathrm{L})$ & $11.2 \pm 4.8$ & $13.9 \pm 5.3$ & .008 & .008 & $1.1(1.0-1.2)$ & 0.66 \\
\hline Lactate clearance $(\mathrm{mmol} / \mathrm{L} \cdot \mathrm{h})$ & $0.44 \pm 0.80$ & $0.02 \pm 0.80$ & .009 & .02 & $0.5(0.3-0.9)$ & 0.68 \\
\hline Regression model of 12-h parameters & & & & & & 0.87 \\
\hline Age (y) & $51.0 \pm 12.2$ & $58.9 \pm 10.7$ & .001 & $<.001$ & $1.1(1.0-1.1)$ & 0.70 \\
\hline Female $(\%)$ & 21.4 & 40.7 & .04 & .001 & $7.7(2.4-25.0)$ & 0.60 \\
\hline Mean lactate concentration $(\mathrm{mmol} / \mathrm{L})$ & $9.4 \pm 4.2$ & $13.3 \pm 5.4$ & $<.001$ & .001 & $1.2(1.1-1.4)$ & 0.71 \\
\hline Lactate clearance $(\mathrm{mmol} / \mathrm{L} \cdot \mathrm{h})$ & $0.55 \pm 0.40$ & $0.23 \pm 0.47$ & .001 & $<.001$ & $0.1(0.02-0.3)$ & 0.72 \\
\hline
\end{tabular}

$\mathrm{C}$ statistics of regression models are shown, as well as single variables. $O R$, Odds ratios; $C I$, confidence interval.

Previous studies have examined the ability of only patient characteristics, during weaning from ECMO, to predict successful weaning. ${ }^{23,24}$ These indicators, however, cannot provide predictions prior to ECMO weaning, or immediately after ECMO initiation. Such early predictions might aid clinicians in determining whether a patient requires further inotrope (such as levosimendan or a phosphodiesterase III inhibitor) infusion and whether an ECMO weaning trial is appropriate.

Lactate levels are affected by macrocirculation to a certain degree. ${ }^{25}$ The results of this investigation revealed negative correlations between the mean lactate concentrations and the average MAP levels at both 6 hours and 12 hours after the initiation of ECMO; higher MAPs were associated with reduced lactate production. Properly elevating the MAP might reduce the production of lactate and potentially influence the outcome. Furthermore, the

TABLE 4. Correlations between the parameters describing the lactate behaviors and those that might have affected the lactate behaviors

\begin{tabular}{lccccc}
\hline & \multicolumn{2}{c}{$\begin{array}{c}\text { Mean lactate } \\
\text { concentration }\end{array}$} & & \multicolumn{2}{c}{$\begin{array}{c}\text { Lactate } \\
\text { clearance }\end{array}$} \\
\cline { 2 - 3 } \cline { 5 - 6 } \multicolumn{1}{c}{ Parameter } & $\mathbf{6 ~ H o u r s ~}$ & $\mathbf{1 2}$ Hours & & 6 Hours & 12 Hours \\
\hline 6-h average MAP level & $-0.350^{*}$ & - & & NS & NS \\
12-h average MAP level & - & $-0.458^{*}$ & & NS & $0.341^{*}$ \\
6-h mean glucose level & $\mathrm{NS}$ & - & & NS & NS \\
12-h mean glucose level & - & NS & & NS & NS \\
Dopamine & NS & $0.215^{\dagger}$ & & NS & $-0.211^{\dagger}$ \\
Epinephrine & $0.236^{*}$ & $0.284^{*}$ & & NS & NS \\
Norepinephrine & $0.288^{*}$ & $0.288^{*}$ & & NS & NS \\
Inotrope score & $0.323^{*}$ & $0.373^{*}$ & & NS & NS \\
ALT & $0.210^{\dagger}$ & $0.287^{*}$ & & NS & $-0.266^{*}$ \\
AST & $0.220^{\dagger}$ & $0.298^{*}$ & & NS & $-0.284^{*}$ \\
ECMO pump flow & NS & NS & & NS & NS \\
6-h RBC transfusions & NS & - & & NS & - \\
12-h RBC transfusions & - & NS & & - & NS \\
\hline
\end{tabular}

$M A P$, Mean artery pressure; $N S$, not significant; $A L T$, alanine aminotransferase; $A S T$, aspartate aminotransferase; $E C M O$, extracorporeal membrane oxygenation; $R B C$, red blood cell. *r value is shown when correlation is significant at the 0.01 level (2-tailed). $\dagger \mathrm{r}$ value is shown when correlation is significant at the 0.05 level (2-tailed). use of greater amounts of an inotrope agent was associated with increased lactate production. Epinephrine might cause increases in lactate levels, owing to the activation of the Na-K-ATPase pump under epinephrine-associated beta-2 $^{\text {stimulation. }}{ }^{26,27}$ Lactate clearance has scarcely been proven to be correlated with the MAP and the inotrope score. Only the 12-hour lactate clearance was positively correlated with the average MAP. Although a previous study suggested that hyperglycemia might stimulate tissue glucose uptake and glycolysis that contributes to hyperlactatemia, ${ }^{28}$ this study did not show any correlation of glucose with lactate level or clearance in a certain period. The liver takes up approximately $60 \%$ of the circulating lactate, and most of that lactate is converted back to pyruvate by the liver. ${ }^{7}$

Transient elevations in blood aminotransferase levels will occur when acute ischemic hepatocellular injury occurs in critically ill patients with circulatory or respiratory failure. $^{29}$ In such situations, lactate clearance is reduced, and lactate might remain at elevated levels; this possibility is in accordance with our results. The levels of alanine aminotransferase and aspartate aminotransferase were positively correlated with lactate concentration and negatively correlated with lactate clearance. Red blood cell transfusion might have been associated with bleeding events. The transfusion of red blood cells maintained the hematocrit at $30 \%$ to $35 \%$; thus, bleeding was less of a problem in terms of the metabolism of lactate.

Our results are consistent with those of a previous study regarding the prediction of the outcomes of postcardiotomy patients. The dynamic performances of lactate can provide early prognostic guidance for adult cardiac surgical patients, and many lactate parameters are independent predictors of death, reoperation, or a set of composite outcomes. ${ }^{15}$ In contrast, one study reported a negative result, in that lactate behavior was not found to be related to the survival of venous-arterial ECMO for refractory cardiac arrest; this result was potentially a result of the small sample size $(n=22)^{30}$ 
Previous studies also indicated that renal insufficiency, the receipt of postoperative renal replacement treatment, leg ischemia, neurologic dysfunction, and other factors ${ }^{1,17,21,22}$ can account for outcomes. In clinical settings, lactate behaviors might provide an overall clinical picture. Any adverse event would be included as an aspect of this picture. Lindsay and colleagues ${ }^{15}$ indicated that lactate behaviors can predict a set of adverse events that includes deep sternal wound infection, permanent stroke, and postoperative renal failure requiring first-time hemodialysis. Thus, we included lactate behaviors in our outcome-predicting analyses only.

Among the limitations of this study are its observational nature and the fact that arterial blood gas was only recorded sequentially. As previously reported, central venous oxygen saturation is another factor that strongly reflects tissue hypoxia. $^{31,32}$ The combination of lactate behavior and central venous oxygen saturation might be more strongly correlated with mortality. Second, further studies should be performed to identify better methods for deriving information for clinical management. Because there was no strictly fixed interval between the acquisitions of the arterial blood gas samples, the lactate clearance was cumbersome to calculate with linear regression. An easier method should be discussed for application in clinical work. Additionally, because of the limitations of a small sample population and the numbers of complications, the relationship between lactate behavior and complications requires further rigorous evaluation. This assessment will be implemented within a larger population in subsequent works.

\section{CONCLUSIONS}

In addition to age and gender (female), early lactate behavior, especially lactate clearance after ECMO support is highly associated with in-hospital mortality in postcardiotomy patients. Additionally, early lactate behavior can predict successful weaning from ECMO.

\section{References}

1. Rastan AJ, Dege A, Mohr M, Doll N, Falk V, Walther T, et al. Early and late outcomes of 517 consecutive adult patients treated with extracorporeal membrane oxygenation for refractory postcardiotomy cardiogenic shock. J Thorac Cardiovasc Surg. 2010;139:302-11.

2. Ko WJ, Lin CY, Chen RJ, Wang SS, Lin FY, Chen YS. Extracorporeal membrane oxygenation support for adult postcardiotomy cardiogenic shock. Ann Thorac Surg. 2002;73:538-45.

3. Bakhtiary F, Keller H, Dogan S, Dzemali O, Oezaslan F, Meininger D, et al. Venoarterial extracorporeal membrane oxygenation for treatment of cardiogenic shock: clinical experiences in 45 adult patients. J Thorac Cardiovasc Surg. 2008;135:382-8.

4. Bartlett RH, Gattinoni L. Current status of extracorporeal life support (ECMO) for cardiopulmonary failure. Minerva Anestesiol. 2010;76:534-40.

5. Magovern GJ Jr, Simpson KA. Extracorporeal membrane oxygenation for adult cardiac support: the Allegheny experience. Ann Thorac Surg. 1999;68:655-61.

6. Bartlett RH, Roloff DW, Custer JR, Younger JG, Hirschl RB. Extracorporeal life support: the University of Michigan experience. JAMA. 2000;283:904-8.

7. Fall PJ, Szerlip HM. Lactic acidosis: from sour milk to septic shock. J Intensive Care Med. 2005;20:255-71

8. Levy MM. Preface biomarkers in critical illness. Crit Care Clin. 2011;27:xiii-xv.
9. Marik PE, Baram M, Vahid B. Does central venous pressure predict fluid responsiveness? A systematic review of the literature and the tale of seven mares. Chest. 2008; 134:172-8.

10. Shapiro NI, Howell MD, Talmor D, Nathanson LA, Lisbon A, Wolfe RE, et al. Serum lactate as a predictor of mortality in emergency department patients with infection. Ann Emerg Med. 2005;45:524-8.

11. Nguyen HB, Rivers EP, Knoblich BP, Jacobsen G, Muzzin A, Ressler JA, et al. Early lactate clearance is associated with improved outcome in severe sepsis and septic shock. Crit Care Med. 2004;32:1637-42.

12. Claridge JA, Crabtree TD, Pelletier SJ, Butler K, Sawyer RG, Young JS. Persistent occult hypoperfusion is associated with a significant increase in infection rate and mortality in major trauma patients. J Trauma Nurs. 2000;48:8-14; discussion 14-15.

13. Meregalli A, Oliveira RP, Friedman G. Occult hypoperfusion is associated with increased mortality in hemodynamically stable, high-risk, surgical patients. Crit Care. 2004;8:R60-5.

14. Basaran M, Sever K, Kafali E, Ugurlucan M, Sayin OA, Tansel T, et al. Serum lactate level has prognostic significance after pediatric cardiac surgery. J Cardiothorac Vasc Anesth. 2006;20:43-7.

15. Lindsay AJ, Xu M, Sessler DI, Blackstone EH, Bashour CA. Lactate clearance time and concentration linked to morbidity and death in cardiac surgical patients. Ann Thorac Surg. 2013;95:486-92.

16. Davies AR, Bellomo R, Raman JS, Gutteridge GA, Buxton BF. High lactate predicts the failure of intraaortic balloon pumping after cardiac surgery. Ann Thorac Surg. 2001;71:1415-20.

17. Wang JG, Han J, Jia YX, Zeng W, Hou XT, Meng X. Outcome of veno-arterial extracorporeal membrane oxygenation for patients undergoing valvular surgery. PLoS One. 2013;8:e63924.

18. Park SJ, Kim SP, Kim JB, Jung S-H, Choo SJ, Chung CH, et al. Blood lactate level during extracorporeal life support as a surrogate marker for survival. $J$ Thorac Cardiovasc Surg. 2014;148:714-20.

19. Kumar TK, Zurakowski D, Dalton H, Talwar S, Allard-Picou A, Duebener LF, et al. Extracorporeal membrane oxygenation in postcardiotomy patients: factors influencing outcome. J Thorac Cardiovasc Surg. 2010;140:330-6.e2.

20. Paden ML, Conrad SA, Rycus PT, Thiagarajan RR, Registry E. Extracorporeal Life Support Organization Registry report 2012. ASAIO J. 2013;59:202-10.

21. Hei F, Lou S, Li J, Yu K, Liu J, Feng Z, et al. Five-year results of 121 consecutive patients treated with extracorporeal membrane oxygenation at Fu Wai Hospital. Artif Organs. 2011;35:572-8.

22. Slottosch I, Liakopoulos O, Kuhn E, Deppe AC, Scherner M, Madershahian N, et al. Outcomes after peripheral extracorporeal membrane oxygenation therapy for postcardiotomy cardiogenic shock: a single-center experience. J Surg Res. 2013;181:e47-55.

23. Aissaoui N, Luyt CE, Leprince P, Trouillet JL, Leger P, Pavie A, et al. Predictors of successful extracorporeal membrane oxygenation (ECMO) weaning after assistance for refractory cardiogenic shock. Intensive Care Med. 2011;37:1738-45.

24. Cavarocchi NC, Pitcher HT, Yang Q, Karbowski P, Miessau J, Hastings HM, et al. Weaning of extracorporeal membrane oxygenation using continuous hemodynamic transesophageal echocardiography. J Thorac Cardiovasc Surg. 2013;146:1474-9.

25. Fuller BM, Dellinger RP. Lactate as a hemodynamic marker in the critically ill. Curr Opin Crit Care. 2012;18:267-72.

26. Levy B, Gibot S, Franck P, Cravoisy A, Bollaert P-E. Relation between muscle $\mathrm{Na}+\mathrm{K}+$ ATPase activity and raised lactate concentrations in septic shock: a prospective study. Lancet. 2005;365:871-5.

27. Levy B, Perez P, Perny J, Thivilier C, Gerard A. Comparison of norepinephrinedobutamine to epinephrine for hemodynamics, lactate metabolism, and organ function variables in cardiogenic shock. A prospective, randomized pilot study. Crit Care Med. 2011;39:450-5.

28. Chioléro RL, Revelly J-P, Leverve X, Gersbach P, Cayeux M-C, Berger MM, et al. Effects of cardiogenic shock on lactate and glucose metabolism after heart surgery. Crit Care Med. 2000;28:3784-91.

29. Bernal W, Wendon J. Acute liver failure. N Engl J Med. 2013;369:2525-34.

30. Attana P, Lazzeri C, Chiostri M, Gensini GF, Valente S. Dynamic behavior of lactate values in venous-arterial extracorporeal membrane oxygenation for refractory cardiac arrest. Resuscitation. 2013;84:e145-6.

31. Hu BY, Laine GA, Wang S, Solis RT. Combined central venous oxygen saturation and lactate as markers of occult hypoperfusion and outcome following cardiac surgery. J Cardiothorac Vasc Anesth. 2012;26:52-7.

32. Laine GA, Hu BY, Wang S, Thomas Solis R, Reul GJ Jr. Isolated high lactate or low central venous oxygen saturation after cardiac surgery and association with outcome. J Cardiothorac Vasc Anesth. 2013;27:1271-6. 